\title{
Relationship Between Maternal Gestational Diabetes and Body Mass Index of 3-Year-Old Children
}

\author{
Maryam Javadian Kutenaie ${ }^{1}$, Parvin Sajadi Kaboodi ${ }^{2}$, Zinatossadat Bouzari ${ }^{3}{ }^{*}$, Mohsen Haghshenas

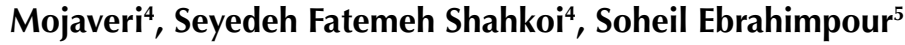

\begin{abstract}
Objectives: The main goal of this study was to investigate the relationship between the maternal gestational diabetes and body mass index (BMI) of three-year-old children.

Materials and Methods: We conducted a descriptive analysis of 100 diabetic pregnant women and 200 healthy pregnant women and their children who were referred to the maternity wards of the teaching hospital of Babol. The measurement of the height and weight of 3-year-old children were done in the clinic.

Results: The average age of mothers participating in this study was $23.73 \pm 3.03$ years. The BMI and the birth weight of infants within the normal weight range in the diabetic group were significantly more than those of non-diabetic children $\left(16.47 \pm 1.42 \mathrm{~kg} / \mathrm{m}^{2}\right.$, $16.09 \pm 1.3 \mathrm{~kg} / \mathrm{m}^{2}, P=0.04,330.33 \pm 214.12 \mathrm{~g}, 3130.65 \pm 242.75 \mathrm{~g}, P=0.001$, respectively). The BMl of the male children of the diabetic group was significantly more than that of the control group at the age of three years although this difference was not significant in girls $\left(16.55 \pm 1.40 \mathrm{~kg} / \mathrm{m}^{2}, 16.01 \pm 1.42 \mathrm{~kg} / \mathrm{m}^{2}, P=0.03\right.$ and $16.36 \pm 1.47 \mathrm{~kg} / \mathrm{m}^{2}, 16.19 \pm 1.31 \mathrm{~kg} / \mathrm{m}^{2}, P=0.53$ for boys and girls, respectively). Conclusions: The findings of the current study showed that the children of mothers with gestational diabetes have a higher BMI compared to their peers although its relationship to gestational diabetes was not significant. However, these findings were significant for boys after gender segregation while not being significant for the girls. Finally, BMI at three years of age had no significant relation with gestational diabetes.

Keywords: Gestational diabetes, Body mass index, Obesity, Diabetes outcome
\end{abstract}

\section{Introduction}

The incidence of diabetes in pregnancy during 19892002 increased by up to $40 \%$ (1). Great attention has been paid to events leading to diabetes, including the uterine microenvironment so that researchers believe that early life events have been controlled in this regard. For example, fetal exposure to maternal hyperglycemia in the womb results in fetal hyperinsulinemia, causing an increase in fetal fat cells, and finally, obesity and insulin resistance in childhood (2). Eventually, this situation leads to impaired glucose tolerance and diabetes in adulthood (3).

Obesity is one of the most serious health problems in many countries of the world which enhances the incidence of cardiovascular diseases $(4,5)$. Childhood obesity creates many complications both during childhood and adulthood (6). The prevalence of obesity in children has increased dramatically. The available information for years 20042006 represents that among persons aged 2-19 years in the United States, $16.3 \%$ were obese having a body mass index (BMI) equal to or above the 95th percentile (7).

Various studies have been conducted on the risk factors associated with obesity in children and adolescents and the findings revealed the most important role of fetal life and the early years of life in children and adolescents obesity (8). The birth weight and birth order in addition to factors such as the duration of breastfeeding and complementary feeding age were associated with obesity in many studies $(9,10)$. BMI in the first trimester of pregnancy is associated with birth weight and the lowest birth rate of the macrosomic infant has been observed in females with a BMI lower than normal (11).

Some studies have shown the relationship between overweight and obesity in children born from mothers with gestational diabetes (12-14). A review article by Kim et al demonstrated a positive association between maternal gestational diabetes and children's overweight and obesity (15). The available evidence indicates the increase in the incidence of cardiovascular disease and metabolic syndrome in children born to mothers with gestational diabetes. However, regional differences, the lack of routine screening, and the treatment of gestational diabetes worldwide, and the long-term follow-up of

Received 11 May 2019, Accepted 7 December 2019, Available online 27 December 2019

${ }^{1}$ Fertility and Infertility Research Health Center, Babol University of Medical Science, Babol, Iran. ${ }^{2}$ Department of Social Medicine, School of Medicine, Babol University of Medical Sciences, Babol, Iran. ${ }^{3}$ Cellular and Molecular Biology Research Center, Obstetrics \& Gynecology Department, Babol University of Medical Sciences, Babol, Iran. ${ }^{4}$ Clinical Research Development Unite of Rouhani Hospital, Babol University of Medical Sciences, Babol, Iran. Infectious Diseases and Tropical Medicine Research Center, Health Research Institute, Babol University of Medical Sciences, Babol, Iran.

*Corresponding Author: Zinatossadat Bouzari, Tel: +989111131229, Email: biouzari.z@yahoo.com 
Key Messages

- The children of mothers with gestational diabetes have a higher BMI.

- The boys of mothers with gestational diabetes have a higher BMI while not being significant for the girls.

children are among the challenges in assessing the risk of the occurrence of gestational diabetes complications and pregnancy-related anomalies in children of mothers with gestational diabetes (16).

Given that there is no information on the rate of obesity in 3-year-old children born to mothers with gestational diabetes in the northern regions of Iran, this study aimed to determine the relationship between mother's gestational diabetes and the BMI of 3-year-old children in Babol in the north of Iran.

\section{Materials and Methods}

The current descriptive-analytical and historical cohort study was carried out on healthy pregnant women or pregnant women with gestational diabetes who were referred to the Maternity Ward of Ayatollah Rouhani and Yahyanejad hospital of Babol University of Medical Sciences in Iran during 2014-2015 for delivery of their children. The sample size according to the formula was considered 100 women with gestational diabetes and 200 healthy women. The inclusion criteria included singleton pregnancy, the lack of congenital anomalies and gestational age of 36-40 weeks, and exclusive breastfeeding for at least 6 months. On the other hand, the exclusion criteria were mothers with chronic high blood pressure, cardiovascular and renal disease, as well as children with chronic diseases, fever and infectious disease during the past two weeks, a history of repeated hospitalizations in infancy to three years, and those who have used from complementary milk at the first year of life with the condition that they are only fed with complementary milk. An accessible and easy sampling method was used for data collection. Using a tailor-made checklist, the data were extracted from the patients' files. This form consisted of three information parts about the mother, the father, and the child. The information related to the mother included the previous pregnancy related-information such as the number of previous pregnancies, parity, number of children and abortions, and the information related to anthropometric indices such as height and weight at the beginning and end of pregnancy and the calculation of BMI based on these indices. The history of the mother's chronic diseases, and in the case of being diabetic, its type, time, and treatment were recorded as well. The information related to the time of infection by the trimester when the mother was infected with it, the types of treatment, and the mother's method of delivery were also recorded in the file of mothers with gestational diabetes. The information related to the child, including gender, age, the rank of the child, weight and height at birth, the duration of breast-feeding, use or nonuse of complementary milk in the first year of the child's life, the onset age of complementary feeding and the history of chronic disease were recorded in the checklist form. Then the parents of both groups were invited to refer to the pediatric clinic of Ayatollah Rouhani Hospital through a phone call for weighing children at three years of age.

In the pediatric clinic, they were reminded that their participation in this research was voluntary, and after obtaining the consent of the family, the three-year-old child's height and weight were evaluated in the clinics. When weighing, the children were wearing a layer of lightweight clothing. Digital scales (Seca, Vogel, and Halke, Hamburg, Germany) and (Seca, Vogel, and Halke) were used to measure their weights and the height gauge, respectively. Information related to the father was completed, including height, weight, BMI and, its type, and the method of control in the case of being diabetic, as well as having a history of diabetes in the family. Mothers were asked about their levels of education including items such as diploma, undergraduate, graduate, and Master of Science. Moreover, the socio-economic level of mothers was divided into non-affluent and affluent categories.

\section{Data Analysis}

Information was collected and entered into the SPSS18 software after encoding. Qualitative and quantitative data were expressed as the frequency and percentage, as well as the mean and standard deviation. Additionally, the Pearson correlation coefficient was used to survey the relationship between quantitative variables and the BMI of the child at the age of three years old. Further, the Spearman correlation coefficient was applied to study the relationship between qualitative variables and BMI. Finally, the chi-square test and independent sample t-test were utilized to compare the children of diabetic and nondiabetic mothers. A $P<0.05$ was considered statistically significant.

\section{Results}

In general, 100 diabetic mothers and 200 non-diabetic mothers participated in this study although 39 women were excluded from the study based on the exclusion criteria. Eighty-four of the women were diabetic while 177 of them were non-diabetic. The mean age of participants and their mean gestational age were $23.73 \pm 3.04$ (18-32 years) and $37.93 \pm 1.08$ (36-40 weeks), respectively. The mean age of mothers in the diabetic and non-diabetic groups was $24.02 \pm 2.99$ years and $23.59 \pm 3.04$ years, respectively. Table 1 provides the demographic data of mothers participating in this study considering the separation of diabetic and non-diabetic groups. The mean age of children in the diabetic and non-diabetic groups was $36.64 \pm 1.11$ months and $36.08 \pm 0.78$ months, respectively. 
Table 1. Qualitative Variables of Diabetic and Non-diabetic Participants

\begin{tabular}{|c|c|c|c|}
\hline Variables & & $\begin{array}{l}\text { Frequency of Diabetic } \\
\text { Participants (\%) }\end{array}$ & $\begin{array}{l}\text { Frequency of Non-diabetic Participants } \\
\qquad(\%)\end{array}$ \\
\hline \multirow{4}{*}{ Gravidity } & 1 & $43(51.2)$ & $110(62.1)$ \\
\hline & 2 & $36(42.9)$ & $51(28.8)$ \\
\hline & 3 & $5(6)$ & $13(7.3)$ \\
\hline & 4 & $0(0)$ & $3(1.7)$ \\
\hline \multirow{3}{*}{ Parity } & 0 & $46(54.8)$ & $116(65.5)$ \\
\hline & 1 & $36(42.9)$ & $51(28.8)$ \\
\hline & 2 & $2(2.4)$ & $10(5.6)$ \\
\hline \multirow{3}{*}{ Live birth } & 0 & $50(59.5)$ & $117(66.1)$ \\
\hline & 1 & $32(38.1)$ & $50(28.2)$ \\
\hline & 2 & $2(2.4)$ & $10(5.6)$ \\
\hline \multirow{3}{*}{ Abortion } & 0 & $78(92.9)$ & $164(92.7)$ \\
\hline & 1 & $6(7.1)$ & $11(6.2)$ \\
\hline & 2 & $0(0)$ & $2(1.1)$ \\
\hline \multirow{4}{*}{ Educational level } & Undergraduate & $19(22.6)$ & $35(19.8)$ \\
\hline & Graduate & $49(58.3)$ & $93(52.5)$ \\
\hline & Diploma & $10(11.9)$ & $44(24.9)$ \\
\hline & Master of science & $6(7.1)$ & $5(2.8)$ \\
\hline \multirow{2}{*}{ Socioeconomic status (income) } & Non affluent & $24(28.6)$ & $21(11.9)$ \\
\hline & Affluent & $60(71.4)$ & $156(88.1)$ \\
\hline \multirow{2}{*}{ Chronic illness } & Yes & $7(8.3)$ & $13(7.3)$ \\
\hline & No & $77(91.7)$ & $164(92.7)$ \\
\hline \multirow{2}{*}{ Deliveries } & Normal vaginal deliveries & $29(34.5)$ & $74(41.8)$ \\
\hline & Caesarean sections & $55(65.5)$ & $103(58.2)$ \\
\hline Gestational age (wk) & Mean \pm SD & $37.61 \pm 0.95$ & $38.08 \pm 1.11$ \\
\hline BMI prior to pregnancy $\left(\mathrm{kg} / \mathrm{m}^{2}\right)$ & Mean \pm SD & $25.72 \pm 3.33$ & $24.12 \pm 3.20$ \\
\hline
\end{tabular}

Note. BMI: Body mass index; SD: Standard deviation.

The birth weight of infants in the diabetic and non-diabetic groups was $3605.47 \pm 316.37 \mathrm{~g}$ and $3250.19 \pm 359.65 \mathrm{~g}$, respectively. The birth height of infants in the diabetic and non-diabetic groups was $50.70 \pm 1.86 \mathrm{~cm}$ and $51.20 \pm 2.88$ $\mathrm{cm}$, respectively. The age of the onset of complementary feeding in the diabetic and non-diabetic groups was $5.92 \pm 0.53$ months and $5.94 \pm 0.36$ months, respectively. The BMI of the three-year-old children in the diabetic group was significantly higher than the children's BMI in the non-diabetic group $(P=0.04)$. The BMI in the threeyear-old children of the diabetic group was significantly more than that of the control group $(P=0.03)$. Table 2 presents the comparison of the weight, height, and BMI of three-year-old children in both diabetic and non-diabetic groups. Based on the results, there was no significant correlation between the BMI of infants in the age of three years with the BMI of fathers $(P=0.47, \mathrm{r}=0.079)$ and the age of mothers $(P=0.64, \mathrm{r}=0.051)$ in the diabetic group. Furthermore, the three-year-old children's BMI in the non-diabetic group had no significant correlation with the BMI of fathers $(P=0.21, \mathrm{r}=0.094)$ and the age of mothers $(P=0.93, \mathrm{r}=0.036)$.

The three-year-old children were divided into 3 subgroups of less than normal weight (less than or equal to a percentile of 5), normal weight (between the percentile of 5 and 85), and overweight (greater than the percentile of 85 ) according to the BMI percentile. Table 3 provides a comparison of the BMI of the three-year-old children participating in the study with the separation of diabetic and non-diabetic mothers. Table 4 presents the correlation

Table 2. Comparison of the Quantitative Variables of the Three-year-old Siblings of Diabetic and Non-diabetic Mothers

\begin{tabular}{|c|c|c|c|}
\hline Variables & Diabetic Participants & Non-diabetic Participants (Mean \pm SD) & $P$ Value \\
\hline Body weight (kg) & $14.36 \pm 1.15$ & $14.07 \pm 1.17$ & 0.06 \\
\hline Height $(\mathrm{cm})$ & $93.45 \pm 2.57$ & $93.54 \pm 2.67$ & 0.7 \\
\hline $\mathrm{BMI}\left(\mathrm{kg} / \mathrm{m}^{2}\right)$ & $16.47 \pm 1.42$ & $16.09 \pm 1.37$ & 0.04 \\
\hline Male child's BMI (kg/m²) & $16.55 \pm 1.40$ & $16.01 \pm 1.42$ & 0.03 \\
\hline Female child's BMI (kg/m²) & $16.36 \pm 1.47$ & $16.19 \pm 1.31$ & 0.53 \\
\hline
\end{tabular}

Note. BMI: Body mass index; SD: Standard deviation. 
Table 3. Comparison of BMI of 3 Years Old Siblings of Diabetics and Nondiabetic Participants

\begin{tabular}{lllll}
\hline Subgroup & Group & Number & Mean \pm SD & P Value \\
\hline Subnormal weight & Diabetic & 7 & $13.91 \pm 0.30$ & 0.82 \\
& Non-diabetic & 23 & $13.87 \pm 0.51$ & \\
\multirow{2}{*}{ Normal weight } & Diabetic & 71 & $16.49 \pm 1.06$ & 0.08 \\
& Non-diabetic & 144 & $16.24 \pm 0.93$ & \\
Overweight & Diabetic & 6 & $19.12 \pm 0.57$ & 0.66 \\
& Non-diabetic & 10 & $19.01 \pm 0.39$ & \\
\hline
\end{tabular}

Note. BMI: Body mass index; SD: Standard deviation.

Table 4. Correlation Between the BMI of Diabetic and Non-diabetic Mothers Prior to Pregnancy and Their 3-Year-Old Siblings

\begin{tabular}{lccc}
\hline Subgroup & Diabetics & Total Number & Non-diabetics \\
\hline Subnormal weight & $r=0.2470$ & $r=0.721$ & $r=0.182$ \\
& $P=0.18$ & $P=0.06$ & $P=0.40$ \\
Normal weight & $r=0.153$ & $r=0.105$ & $r=0.144$ \\
Overweight & $P=0.02$ & $P=0.38$ & $P=0.08$ \\
& $r=-0.113$ & $r=-0.007$ & $r=0.219$ \\
& $P=0.67$ & $P=0.99$ & $P=0.54$ \\
\hline
\end{tabular}

Note. BMI: Body mass index; SD: Standard deviation.

coefficient of the BMI of mothers before pregnancy with the BMI of the three-year-old children in general and given the separation of diabetic and non-diabetic groups.

\section{Discussion}

The current research was designed and conducted aiming at investigating the relationship between gestational diabetes and the BMI of three-year-old children. The results of this study showed that the average of the BMI in these children in the diabetes group was significantly higher than the BMI of children in the non-diabetic group although these findings were significant for boys after gender segregation but not significant for the girls. Based on the results, there was no significant relationship between the gestational diabetes of mothers and children's $\mathrm{BMI}$ in this age group.

The study of Wright et al in America demonstrated that there was no significant difference between children's BMI in the three groups of non-diabetic mothers, women with impaired glucose tolerance, and those with gestational diabetes (17), which contradicts the results of our study. In other words, the mean age of mothers in the American study was extremely higher than that of our study.

Although our findings are in line with those of the study of Zhang et al, they reported that the children of diabetic mothers had higher average height compared to the non-diabetic group. In addition, other studies (18-20) indicated that children born to mothers with gestational diabetes have a weight and height above the normal mothers, which is inconsistent with the findings of our study. In our study, the children's height of non-diabetic mothers was higher than the children's height of diabetic mothers although this difference was not significant. The difference in the race of participants in the study could be one of the causes of the differences in the above results (21).

Based on the results of the study of Baptiste-Roberts et al in America on diabetic and non-diabetic women, there was no significant difference between the BMI of two diabetic and non-diabetic groups, which contradicts the results of our study. One reason for the difference in the above results is related to the long interval between birth and the age of three years old and different environmental factors including diet affect the development of children (22). However, some studies showed that women with gestational diabetes mellitus are at an elevated risk of developing type 2 diabetes mellitus in the years after childbirth and having overweight children (23-25).

In our study, the birth weight of neonates had a significant correlation with the BMI of the three-yearold children weighing less than normal, which is similar to the results of Tanaka et al in Japan and Binkin et al in the United States $(26,27)$. Obesity and weight both largely depend on genetic factors but other causes such as the abnormal mechanisms of lipid metabolism, as well as the amount of nutrition and energy expenditure may have an important role as well $(28,29)$. According to the findings of this study, many factors affect the BMI of diabetic mothers' children at the age of three, therefore, more research is needed to investigate the relationship between gestational diabetes and BMI in childhood and to remove confounding factors. In conclusion, the results revealed the average BMI in the three-year-old children of the diabetic group was significantly higher than that of the children of the non-diabetic group. After gender segregation, the BMI in the three-year-old children of the diabetic group was significantly higher than that of the children of the non-diabetic group, but there was no significant correlation between the gestational diabetes of mothers with BMI in the three-year-old children. Finally, there was no significant relationship between birth weight and BMI at age three.

\begin{abstract}
Authors' Contribution
$\mathrm{ZB}, \mathrm{MJ}$ and PS conceived the research question, designed the protocol, and were involved in the literature search, study selection, and data extraction. FSh, MH and SE contributed to data acquisition, analysis, and interpretation. RS and SY created the tables, figures, and. ZB and $M M$ contributed to both the draft and final versions of the manuscript. $\mathrm{ZB}, \mathrm{MJ}, \mathrm{FSh}, \mathrm{MH}$, and SE contributed to study design/conduct/analysis and the write-up of the paper.
\end{abstract}

Conflict of Interests

Authors declare that they have no conflict of interests.

Ethical Issues

This research was reviewed and approved by the Ethics Committee of Babol University of Medical Sciences (MUBABOL.REC.1392.11).

\section{Financial Support}

The budget of the present study was provided by Babol University of Medical Sciences. 


\section{Acknowledgments}

We would like to acknowledge the cooperation of the Vice-chancellor of Research and Technology of the Medical Sciences University of Babol.

\section{References}

1. Russell C, Dodds L, Armson BA, Kephart G, Joseph KS. Diabetes mellitus following gestational diabetes: role of subsequent pregnancy. Bjog. 2008;115(2):253-259. doi:10.1111/j.14710528.2007.01459.x

2. Ruchat SM, Hivert MF, Bouchard L. Epigenetic programming of obesity and diabetes by in utero exposure to gestational diabetes mellitus. Nutr Rev. 2013;71 Suppl 1:S88-94. doi:10.1111/ nure. 12057

3. Kelstrup L, Clausen TD, Mathiesen ER, Hansen T, Holst JJ, Damm P. Incretin and glucagon levels in adult offspring exposed to maternal diabetes in pregnancy. J Clin Endocrinol Metab. 2015;100(5):19671975. doi:10.1210/jc.2014-3978

4. Lavie CJ, McAuley PA, Church TS, Milani RV, Blair SN. Obesity and cardiovascular diseases: implications regarding fitness, fatness, and severity in the obesity paradox. J Am Coll Cardiol. 2014;63(14):1345-1354. doi:10.1016/j.jacc.2014.01.022

5. Scherer PE, Hill JA. Obesity, diabetes, and cardiovascular diseases: a compendium. Circ Res. 2016;118(11):1703-1705. doi:10.1161/ circresaha.116.308999

6. Pulgarón ER. Childhood obesity: a review of increased risk for physical and psychological comorbidities. Clin Ther. 2013;35(1):A18-32. doi:10.1016/j.clinthera.2012.12.014

7. Kliegman R. Nelson Textbook of Pediatrics. Philadelphia, PA: Saunders Elsevier; 2011. 2013.

8. Haire-Joshu D, Tabak R. Preventing obesity across generations: evidence for early life intervention. Annu Rev Public Health. 2016;37:253-271. doi:10.1146/annurevpublhealth-032315-021859

9. Johnson L, van Jaarsveld $\mathrm{CH}$, Llewellyn $\mathrm{CH}$, Cole TJ, Wardle J. Associations between infant feeding and the size, tempo and velocity of infant weight gain: SITAR analysis of the Gemini twin birth cohort. Int J Obes (Lond). 2014;38(7):980-987. doi:10.1038/ ijo.2014.61

10. Celi F, Bini V, De Giorgi G, et al. Epidemiology of overweight and obesity among school children and adolescents in three provinces of central Italy, 1993-2001: study of potential influencing variables. Eur J Clin Nutr. 2003;57(9):1045-1051. doi:10.1038/ sj.ejcn. 1601640

11. Yazdani S, Yosofniyapasha $\mathrm{Y}, \mathrm{Nasab} \mathrm{BH}$, Haghshenas Mojaveri $M$, Bouzari Z. Effect of maternal body mass index on pregnancy outcome and newborn weight. BMC Res Notes. 2012;5:34. doi:10.1186/1756-0500-5-34

12. Boerschmann H, Pflüger M, Henneberger L, Ziegler AG, Hummel $\mathrm{S}$. Prevalence and predictors of overweight and insulin resistance in offspring of mothers with gestational diabetes mellitus. Diabetes Care. 2010;33(8):1845-1849. doi:10.2337/dc10-0139

13. Ouyang F, Parker MG, Luo ZC, et al. Maternal BMI, gestational diabetes, and weight gain in relation to childhood obesity: the mediation effect of placental weight. Obesity (Silver Spring). 2016;24(4):938-946. doi:10.1002/oby.21416

14. Herring SJ, Oken E. Obesity and diabetes in mothers and their children: can we stop the intergenerational cycle? Curr Diab Rep. 2011;11(1):20-27. doi:10.1007/s11892-010-0156-9
15. Kim SY, Sharma AJ, Callaghan WM. Gestational diabetes and childhood obesity: what is the link? Curr Opin Obstet Gynecol. 2012;24(6):376-381. doi:10.1097/GCO.0b013e328359fOf4

16. Garcia-Vargas L, Addison SS, Nistala R, Kurukulasuriya D, Sowers JR. Gestational diabetes and the offspring: implications in the development of the cardiorenal metabolic syndrome in offspring. Cardiorenal Med. 2012;2(2):134-142. doi:10.1159/000337734

17. Wright CS, Rifas-Shiman SL, Rich-Edwards JW, Taveras EM, Gillman MW, Oken E. Intrauterine exposure to gestational diabetes, child adiposity, and blood pressure. Am J Hypertens. 2009;22(2):215220. doi:10.1038/ajh.2008.326

18. Zhang S, Liu H, Zhang $\mathrm{C}$, et al. Maternal glucose during pregnancy and after delivery in women with gestational diabetes mellitus on overweight status of their children. Biomed Res Int. 2015;2015:543038. doi:10.1155/2015/543038

19. Pettitt DJ, Nelson RG, Saad MF, Bennett PH, Knowler WC. Diabetes and obesity in the offspring of Pima Indian women with diabetes during pregnancy. Diabetes Care. 1993;16(1):310-314. doi:10.2337/diacare.16.1.310

20. Lawlor DA, Lichtenstein P, Långström N. Association of maternal diabetes mellitus in pregnancy with offspring adiposity into early adulthood: sibling study in a prospective cohort of 280,866 men from 248,293 families. Circulation. 2011;123(3):258-265. doi:10.1161/circulationaha.110.980169

21. Janjua NZ, Mahmood B, Islam MA, Goldenberg RL. Maternal and early childhood risk factors for overweight and obesity among low-income predominantly black children at age five years: a prospective cohort study. J Obes. 2012;2012:457173. doi:10.1155/2012/457173

22. Baptiste-Roberts K, Nicholson WK, Wang NY, Brancati FL. Gestational diabetes and subsequent growth patterns of offspring: the National Collaborative Perinatal Project. Matern Child Health J. 2012;16(1):125-132. doi:10.1007/s10995-011-0756-2

23. Herath $H$, Herath $R$, Wickremasinghe R. Gestational diabetes mellitus and risk of type 2 diabetes 10 years after the index pregnancy in Sri Lankan women-A community based retrospective cohort study. PLoS One. 2017;12(6):e0179647. doi:10.1371/ journal.pone.0179647

24. Yogev $\mathrm{Y}$, Visser GH. Obesity, gestational diabetes and pregnancy outcome. Semin Fetal Neonatal Med. 2009;14(2):77-84. doi:10.1016/j.siny.2008.09.002

25. Ornoy A. Prenatal origin of obesity and their complications: Gestational diabetes, maternal overweight and the paradoxical effects of fetal growth restriction and macrosomia. Reprod Toxicol. 2011;32(2):205-212. doi:10.1016/j.reprotox.2011.05.002

26. Binkin NJ, Yip R, Fleshood L, Trowbridge FL. Birth weight and childhood growth. Pediatrics. 1988;82(6):828-834.

27. Tanaka T, Matsuzaki A, Kuromaru R, et al. Association between birthweight and body mass index at 3 years of age. Pediatr Int. 2001;43(6):641-646. doi:10.1046/j.1442-200x.2001.01468.x

28. Llewellyn C, Wardle J. Behavioral susceptibility to obesity: geneenvironment interplay in the development of weight. Physiol Behav. 2015;152(Pt B):494-501. doi:10.1016/j.physbeh.2015.07.006

29. Klop B, Elte JW, Cabezas MC. Dyslipidemia in obesity: mechanisms and potential targets. Nutrients. 2013;5(4):12181240. doi:10.3390/nu5041218

(C) 2021 The Author(s); This is an open-access article distributed under the terms of the Creative Commons Attribution License (http:// creativecommons.org/licenses/by/4.0), which permits unrestricted use, distribution, and reproduction in any medium, provided the original work is properly cited. 